\title{
Os Novos Desafios dos Professores de IES no Pós Pandemia: Um Estudo Realizado Com Docentes das Instituições de Ensino Superior de Juazeiro do Norte - Ceará
}

\author{
Marcus Vinicius Cruz Cordeiro ${ }^{1}$; Nágila Batista Coelho ${ }^{2}$; Piedley Macedo Saraiva ${ }^{3}$; \\ Tayronne de Almeida Rodrigues ${ }^{4}$; Adriana de Alencar Gomes Pinheiro ${ }^{5}$
}

\begin{abstract}
Resumo: Este trabalho objetivou verificar os desafios encontrados pelo corpo docente para superar as dificuldades do ensino geradas na Pandemia da COVID-19, bem como os modelos adotados para uma melhoria na qualidade de ensino por meio de um grupo de professores das Instituições de Ensino Superior da rede pública e privada de Juazeiro do Norte-CE. Os professores relataram vários desafios enfrentados nas instituições com a retomada das aulas e diversas questões a serem discutidas no ensino pós Pandemia relacionado ao modelo semipresencial, remoto e EAD, entre eles a falta de recursos tecnológicos, treinamento específico e falta de domínio das ferramentas. Os professores também colocaram que para um ensino pós Pandemia será necessário investir em recursos tecnológicos, capacitação de docentes e discente e mais investimento das instituições públicas e privadas. A Metodologia aplicada neste trabalho foi a pesquisa bibliográfica de natureza qualitativa, descritiva, exploratória e entrevista com instrumento de coleta de dados.
\end{abstract}

Palavras-chave: Ensino Superior. Pandemia. COVID-19. Ensino Remoto.

\footnotetext{
${ }^{1}$ Mestrando em Desenvolvimento Regional Sustentável pela Universidade Federal do Cariri. Especialização em Educação Profissional Integrada a Educação Básica na Modalidade de Jovens e Adultos pelo Instituto Federal de Educação, Ciência e Tecnologia do Ceará (2010). Graduação em Direito pela Universidade Regional do Cariri (2005). marcus@ifce.edu.br;

${ }^{2}$ Mestranda em Desenvolvimento Regional Sustentável pela Universidade Federal do Cariri. Especialização em Arqueologia Social Inclusiva pela Universidade Regional do Cariri e o Instituto de Arqueologia do Cariri em parceria com a Fundação Casa Grande (2018). Graduação em História pela Universidade Regional do Cariri URCA (2017). nagilabatista334@ gmail.com;

${ }^{3}$ Mestrando em Desenvolvimento Regional Sustentável pela Universidade Federal do Cariri, Mestrado profissional em Administração de Empresas pela Uniamericas com concentração em Gestão estratégica. Especialista em Competências Gerenciais pela FALS (2005), em Formação de Professores do Ensino Superior pela Faculdade Católica do Cariri (2012) em Gestão estratégica pela Stella Maris (2014), MBA em Marketing digital pela Estácio de Sá, cursando Especialização em Metodologia de Gestão em EAD. Graduação em Administração de empresas pela Universidade Federal da Paraíba (2004). Técnico em transações imobiliárias pelo CETREDE. Atuação na área comercial e de marketing. Analista de Mercado do Senai CFP WCC. Ministra aulas desde 2004 em Faculdades de Juazeiro do Norte e em Cursos técnicos desde 2001. Leciona em cursos de graduação, especialização e MBA. Atualmente professor do Centro Universitário Paraíso em Juazeiro do Norte-CE. piedley@vucca.com.br;

${ }^{4}$ Mestrando em Desenvolvimento Regional Sustentável pela Universidade Federal do Cariri. Especialização em Docência do Ensino Superior (2019). Graduação em Filosofia pela Faculdade Entre Rios do Piauí (2017). Professor vinculado a Secretária da Educação do Estado do Ceará (SEDUC). tayronnealmeid@ gmail.com;

${ }^{5}$ Doutora e Mestre em Psicologia pela Universidade de Fortaleza (UNIFOR). Líder do Núcleo de Estudo e Pesquisa em Subjetividades, Bioética e Políticas Públicas (NESBPOP). Graduada em Psicologia pela Universidade de Fortaleza (UNIFOR) e em Ciências Sociais pela Universidade Católica de Pernambuco (UNICAP). Professora do Mestrado em Desenvolvimento Regional Sustentável, linha de pesquisa saúde, estado e sociedade do PRODER/UFCA. Coordenadora e professora do Curso de Psicologia do Centro Universitário Paraíso (UNIFAP) de Juazeiro do Norte, Ceará. Membro da Associação Nacional de Pesquisa e Pós-graduação em Psicologia (ANPEPP). adriana.alencar@ fapce.edu.br.
} 


\title{
The New Challenges of University Teachers in Post Pandemic: A Study Conducted with Teachers from Higher Education Institutions in Juazeiro do Norte - Ceará
}

\begin{abstract}
This work aimed to verify the challenges faced by the faculty to overcome the teaching difficulties generated in the COVID-19 Pandemic, as well as the models adopted to improve the quality of teaching through a group of teachers from the Higher Education Institutions of the network public and private sector in Juazeiro do Norte-CE. The teachers reported several challenges faced in the institutions with the resumption of classes and several issues to be discussed in post Pandemic teaching related to the semi-presence, remote and distance learning model, among them the lack of technological resources, specific training and lack of mastery of the tools. Teachers also stated that for post Pandemic education, it will be necessary to invest in technological resources, training of teachers and students and more investment by public and private institutions. The methodology applied in this work was a qualitative, descriptive, exploratory bibliographic research and interview with a data collection instrument.
\end{abstract}

Keywords: Higher Education. Pandemic. COVID-19. Remote Education.

\section{Introdução}

O mundo está passando por uma séria transformação, isso se deve principalmente devido ao caos ocasionado pelo COVID-19, este fato pegou várias organizações, tanto públicas como privadas, de surpresa, exigindo a mudança emergencial de seus processos. Um dos setores que foi mais impactado com este fator foi o setor educacional, onde as três cadeias que a compõe, (instituição, docentes e discentes) tiveram que se readequar.

Quando se fala sobre ensino a distância, a primeira coisa que se pensa é a tecnologia. A seguir, vem a ideia de que é um método de ensino recente. Porém, a história do EAD começou há quase três séculos. De acordo com Alves (2009) o primeiro relato de um curso feito sem aulas presenciais e no tempo do aluno, foi no ano de 1728, no jornal norteamericano Gazeta de Boston.

No Brasil, a EAD é marcada por períodos de sucesso e estagnação, conforme aponta Alves (2009). O segundo período resulta de falta de políticas públicas para o setor. Entretanto, a modalidade tem um papel importante na democratização do ensino, destinada principalmente aos cidadãos que estão fora das regiões mais favorecidas.

Baseado neste pressuposto propõe-se através deste trabalho tentar resolver a seguinte problemática: Como os Docentes estão se posicionando para conseguir superar as dificuldades de aprendizado gerada na Pandemia? E como objetivo geral buscou-se identificar os modelos adotados por docentes para melhoria na qualidade de ensino neste novo tempo. 
Para alcançar o objetivo desse estudo foi realizado uma entrevista junto a quatro professores de ensino superior de instituições públicas e privadas a fim de evidenciar as dificuldades enfrentadas por eles neste novo momento, avaliar o apoio gerado pelas instituições de ensino a fim de auxiliar no processo ensino aprendizagem e entender as principais técnicas adotadas pelos docentes.

Este trabalho será dividido em cinco capítulos. Em seu primeiro capítulo serão apresentados: tema, problemática, objetivo geral e específicos. No segundo, será realizado um levantamento bibliográfico a fim de embasar o trabalho, segmentado em três blocos, sendo no primeiro apresentando modelo de aula remota; no segundo bloco, será discutida a educação totalmente a distância; e no terceiro, serão apresentadas o modelo hibrido de educação integrando remota, educação a distância e o semipresencial. Após, será apresentada a metodologia utilizada para coleta e análise dos resultados. No quarto capítulo, serão apresentados os dados coletados pela pesquisa, com sua discussão. Finalizando, far-se-á considerações finais sobre o que foi descoberto e recomendações para posteriores pesquisas.

\section{Fundamentação Teórica}

A Pandemia da COVID-19 revolucionou o mundo, trazendo diversas transformações em todos os setores de forma brusca e avançada. Dentre todos esses setores a educação foi a mais afetada, desde o ensino básico até o ensino universitário, docentes, discentes, gestores e comunidade em geral, foram todos surpreendidos, tendo que se adaptar rapidamente a todas essas mudanças e a incluir recursos tecnológicos no âmbito educacional, sem formações e recursos para tais mudanças (RODRIGUES et al., 2020).

Apesar de ser um problema educacional, o fechamento das escolas, remodelou parte da sociedade, pois as famílias passaram a exercer e conciliar múltiplas funções ao mesmo tempo, funções acadêmicas, profissionais e familiares e isso gerou desconforto e descontentamento, já que por ser desconhecido, o Coronavírus não permite um planejamento de acolhimento a todos os envolvidos com destaque à este contexto educacional, tendo em vista que não foi possível planejar e executar decisões a médio prazo, fazendo com que governos no mundo todo, tomem diferentes decisões diariamente conforme o índice de mortos e contaminados.

A educação e a sua importância sobressaíram, tiveram grande destaque, professores de todos os níveis e modalidades de ensino têm se reinventado diariamente em suas práticas pedagógicas e começaram a utilizar massivamente em seus planejamentos educacionais 
tecnologias da informação e comunicação mesmo sem formação ou conhecimento básico necessário para tal. Como os docentes que não vivem a experiência de utilizar as tecnologias da informação e comunicação irão adaptá-las e inseri-las no processo de ensino e aprendizagem, diagnosticando e opinando sobre algo que nem mesmo conhecem? É necessário que se reflita esta questão, que políticas e programas de inclusão tecnológicas sejam desenvolvidas no setor público e privado, sendo inseridas na formação inicial do professor e nas formações continuadas.

Essa gama de possibilidades, modernidades e conhecimentos que a Pandemia trouxe para o cenário educacional, não tem sido tarefa fácil tendo em vista quanto à formação de professores:

[...] tanto inicial como continuada, poucas e incipientes têm sido as iniciativas capazes de apontar saídas reais ou de contribuírem de forma eficiente com um trabalho que integre a questão da aprendizagem, enquanto promotora de desenvolvimento cognitivo dos alunos com os instrumentos tecnológicos como o computador e a internet. (Freitas, 2009, p. 09).

Nesse contexto pandêmico os docentes sentem-se cada vez mais pressionados, pois faltou uma formação necessária e até mesmo recursos didáticos tecnológicos, e também "a ênfase dada à tecnologia aparece como uma coqueluche" (EICHILER et al., 2003, p.2). Assim como no ensino básico, público e privado, que funcionava apenas na modalidade presencial, algumas Instituições de Ensino Superior que também utilizavam apenas da mesma modalidade, aderiram ao ensino remoto durante a Pandemia, outras aderiram ao ensino EAD (educação a distância) ou ao ensino semipresencial.

Apesar das inúmeras dificuldades encontradas no setor educacional, como falta de recursos e formações pedagógicas adequadas e eficientes, observa-se que as respostas obtidas pelos educadores através do uso das tecnologias, foram na grande maioria significativas, fazendo com que os profisssionais da educação adaptassem seus planejamentos de aulas do dia para a noite, sem formação, recursos ou tempo hábil para tal, improvisando para realizar gravações e transmissão de aulas através de mídias sociais e algumas plataformas digitais como Google Meet, Zoom, Microsoft Teams, entre outros, demonstrando muitas iniciativas no sentido de considerar a atual situação pandêmica e todas as mudanças que ela tem ocasionado na vida da população. 


\section{Modelo de aulas on-line (aulas remotas)}

Apesar da Pandemia da COVID-19 ter modificado a rotina da população a nível mundial, surgiram muitas 'soluções' de ensino a distância, as quais se fizeram necessárias dentro desse contexto, porém deve ser considerado o seu efeito limitado, levando em consideração a falta de equidade no tocante ao acesso da população às mídias sociais e a falta de recursos e formações eficientes para os docentes. Devido essa falta de interação presencial, as dificuldades encontradas pelos educadores e seus educandos formaram muitas lacunas nas áreas de conhecimentos previamente definidos pelo setor educacional e na interação social, sendo necessária cautela com a normatização e a equivalência das horas aplicadas nesta modalidade de ensino, assim como o cumprimento de períodos letivos.

O modelo de aulas remotas ou on-line, é o modelo que foi acolhido por diversas instituições de ensino no início da Pandemia, como forma de solução imediata, o qual apresentou uma menor resistência no ensino superior.

O ensino remoto, tem como princípio básico manter o vínculo entre professores, alunos e profissionais da educação, levando em consideração que o ensino remoto não se restringe apenas à existência ou não do acesso tecnológico, compreendendo a complexidade de ter docentes e discentes confinados, os quais se encontram em condições de fragilidades proporcionadas pelo momento, que sequer tiveram formações e períodos de ambientação para uso de tecnologias. Considerando a Pandemia de Coronavírus e com intuito de manter o vínculo entre docentes e discentes o Ministério da Educação e Cultura (MEC) institui a Portaria No 343, de 17 de março de 2020 que diz o seguinte:

\footnotetext{
Art. $1^{\circ}$ Autorizar, em caráter excepcional, a substituição das disciplinas presenciais, em andamento, por aulas que utilizem meios e tecnologias de informação e comunicação, nos limites estabelecidos pela legislação em vigor, por instituição de educação básica e superior, integrantes do sistema federal de ensino, de que trata o art. $2^{\circ}$ do Decreto $\mathrm{n}^{\circ}$ 9.235, de 15 de dezembro de 2017 (BRASIL, 2020, p.01).
}

Esta modalidade de ensino pode acontecer através de lives, redes sociais, plataformas interativas, durante horários específicos das aulas, de modo a permitir a interação em tempo real, de maneira simultânea e síncrona, ou de modo assíncrono, utilizando outras ferramentas educacionais e tecnológicas como gravações de videoaulas e materiais disponibilizados para consultas e explicações 


\section{Modelo EAD}

A educação a distância, conhecida por EAD, é um modelo de ensino recente aqui no Brasil, onde acontecem aulas de forma assíncrona (não instantânea), planejada e estruturada, seja de forma tecnológica através de meios digitais ou de forma analógica com materiais impressos e estruturados por disciplinas e áreas de conhecimento, como livros. O Brasil tem uma legislação que engloba a concepção de EAD, a qual reflete os referenciais teóricos internacionais. De acordo com o parágrafo $1^{\circ}$ do Decreto $n^{\circ}$ 9057/2017:

\footnotetext{
Para os fins deste Decreto, considera-se educação a distância a modalidade educacional na qual a mediação didático-pedagógica nos processos de ensino e aprendizagem ocorra com a utilização de meios e tecnologias de informação e comunicação, com pessoal qualificado, com políticas de acesso, com acompanhamento e avaliação compatíveis, entre outros, e desenvolva atividades educativas por estudantes e profissionais da educação que estejam em lugares e tempos diversos. (BRASIL, 2017).
}

Apresentaria um questionamento nessa concepção, pois a expressão "com pessoal qualificado" é um reflexo da ideia de que EAD não tem a mesma qualidade que a educação presencial, sabendo-se o que é necessário para se definir uma modalidade nova e amplamente regulamentada, se faz necessário informar que os profissionais que trabalham nessa modalidade são "competentes e qualificados”, como se fosse possível não ser. Hodges et al. (2020), afirma que esta ideia de antagonismos de qualidade é recorrente em nível mundial. Percebemos que nesse contexto de Pandemia da COVID-19, muitas instituições têm colocado em prática alternativas rápidas que envolvem erroneamente as tecnologias como se fossem experiências de educação a distância, sem nem mesmo ter muitas vezes, estrutura para tal.

As Instituições de Ensino Superior nesse período de Pandemia terão certamente papel nas mudanças de paradigmas de que o ensino a distância no Brasil é inferior ao presencial, pois mesmo que contrárias a esta modalidade, devido ao atual contexto tiveram que aderir ao EAD, e geralmente atingindo resultados satisfatórios de recursos simples e inúmeras possibilidades de inovações que este formato nos oferece.

Conforme afirmam Maia e Mattar (2008), o ensino a distância requer estudos, organizações e planejamento anterior, considerando o perfil de educadores e educandos, as objetivos do curso em questão, desenvolvimento de estratégias de ensino e aprendizagem, levando em consideração as modalidades síncronas e assíncronas de um ensino a distância eficaz e de qualidade, com o intuito de obter e atingir o máximo de aproveitando possível, envolvendo a participação de múltiplos profissionais para o desenvolvimento educacional como 
um todo, contendo qualidade pedagógica, visual e atrativa, com materiais diversos que servem de apoio para o professor.

\section{Modelo semipresencial}

O modelo de ensino semipresencial, ou modelo híbrido, é a junção de duas modalidades que coexistem entre si, com atividades presenciais e a distância.

A carga horária presencial é definida pela instituição de ensino, de acordo com as necessidades de cada curso. Nesta modalidade de ensino híbrido, o discente tem acesso a um ambiente de aprendizagem virtual, onde constam todas as informações necessárias para a sua formação acadêmica, com algumas aulas presenciais, conforme preestabelecido pela instituição de ensino.

Este modelo educacional é muito comum em cursos de nível superior, e tem sido muito adotado pelas instituições educacionais, visto que aumentou consideravelmente a demanda pela procura dessa modalidade devido a sua flexibilidade de horários que devem ser cumpridos de forma presencial na instituição de ensino. Cursar um ensino semipresencial é algo inovador, que proporciona flexibilidade quanto aos horários de estudo e os dias de aulas presenciais, porém requer muita disciplina e dedicação (MARTINS; ALMEIDA, 2020).

Os docentes desta modalidade híbrida possuem formações pedagógicas e tecnológicas para lidar com as novas metodologias de ensino, embora esta modalidade sofra preconceitos é importante ressaltar que a tecnologia está presente no cotidiano da sociedade, sendo necessário a criação de políticas que as implementem do ensino básico até o ensino superior facilitando o acesso para todos. Apesar de muitas Instituições de Ensino Superior ainda não serem adeptas ao ensino híbrido, durante a Pandemia da COVID-19 isso mudou, e diversas instituições de ensino acabaram aderindo as tecnologias educacionais mesmo que de forma emergencial e provavelmente continuem utilizando-as após esse período, seja como complementação dos recursos educacionais já conhecidos ou até mesmo a sua implementação na grade curricular em diversas modalidades do conhecimento.

Diante de uma Pandemia, podemos perceber que não se trata apenas de escolher uma modalidade de ensino que seja mais eficaz, e sim da necessidade de discutir algo inédito, como a inserção de tecnologias no meio educacional, onde rapidamente as informações são atualizadas e não se tem protocolos seguros para retornar ao modelo educacional como vivíamos antes do período de Coronavírus. É necessário que haja conscientização da 
importância de se criar políticas públicas que ressaltem a importância de incluir tecnologias no ensino básico e superior, que englobem a formação de professores e até a equidade de acesso pela população. Além disso, conforme afirmam Lopes e Furkotter (2016), integrar tecnologia no ensino superior, sobretudo na formação inicial de professores, desafia-os a encontrar modos de ensinar com tecnologia, que o levem a refletir sobre os limites e as possibilidades desse uso na escola básica. É extremamente importante ressaltar que mesmo em diferentes modalidades de ensino, seja presencial, semipresencial ou EAD, a educação se faz necessária, o professor se torna cada vez mais necessário, pois mesmo diante de todas as dificuldades, encontrou maneiras de driblá-las e exercer o seu importante papel perante a sociedade, em um momento de crise, de algo inédito e desconhecido, à nível mundial.

\section{Metodologia}

A metodologia aplicada neste trabalho foi um estudo descritivo de natureza qualitativa realizado através de instrumento de pesquisa entrevista. Segundo Malhotra (2004), uma pesquisa pode ser orientada em seis diferentes etapas: definição de problema, desenvolvimento da abordagem, formulação da concepção da pesquisa, coleta de dados, preparação e análise de dados, preparação e apresentação do relatório.

Segundo Lakatos e Marconi (2010), as abordagens qualitativas têm o poder de analisar aspectos complexos de fenômenos sociais considerando o contexto, buscando entender as experiências humanas de forma pessoal ou grupal.

Para Leite (2008, p. 94), “a divisão entre pesquisa qualitativa e quantitativa é apenas teórica, porque na prática toda e qualquer pesquisa usa os dois tipos de métodos sempre”, sendo, portanto, pesquisas auxiliares uma da outra. Ainda segundo Leite (2008, p.96), as abordagens qualitativas "são as que empregam a estatística e a matemática - os números e cálculos - como principal recurso para a análise das informações".

De acordo com Gonçalves (2004, p.45),

\footnotetext{
"uma pesquisa não consiste simplesmente da divulgação dos seus resultados para o público, mas também contribui para o aprofundamento e a compreensão com relação a um determinado tema abordado."
} 
Para a mesma foi importante realizar uma pesquisa descritiva, pois segundo Cervo e Bervian (2002, p.66), este tipo de pesquisa "busca conhecer as diversas situações que ocorrem na vida social, política, econômica e os demais aspectos do comportamento humano, tanto do indivíduo tomado isoladamente como de grupos e comunidades mais complexas". Fundamentar-se-á em pesquisa bibliográfica e de campo, com caráter exploratório.

Conforme dado o objetivo geral deste trabalho, buscou-se identificar os modelos adotados por docentes para melhoria na qualidade de ensino neste novo tempo, optou-se por aplicar como instrumento de coleta de dados uma entrevista, onde o pesquisador realizou perguntas abertas e fechadas, que foram respondidas por meio de aplicação de questionário estruturado a docentes de IES públicas e privadas entre os dias 01 a 10 de outubro de 2020.

O autor Leite (2008, p.75), afirma que:

\footnotetext{
"a entrevista é uma conversa verbal face a face que permite ao entrevistador informações para a pesquisa. Os dados coletados serão analisados por meio da interpretação das respostas obtidas, através da análise de conteúdo.”
}

A entrevista foi elaborada com perguntas estruturadas, tanto abertas como fechadas, voltadas para compreender a percepção que os docentes nos cursos de graduação à distância têm sobre essas modalidades de ensinos. Optou-se por aplicar a entrevista em quatro IES localizadas em Juazeiro do Norte - CE.

\section{Resultados e Discussões}

As considerações apresentadas pelos entrevistados nos dão um panorama local sobre a mudanças e perspectivas adotadas no contexto de ensino e aprendizagem. Desde a transição, dificuldades, mudanças positivas, visão, impactos presentes e futuros, e perspectivas da educação brasileira no momento pós Pandemia. 
Quadro 01 - Perfil dos entrevistados:

\begin{tabular}{|l|c|c|c|c|c|c|}
\hline \multicolumn{1}{|c|}{ Id. } & $\begin{array}{c}\text { Faixa } \\
\text { etária } \\
\text { (anos) }\end{array}$ & $\begin{array}{c}\text { Tempo de } \\
\text { atividade } \\
\text { docente } \\
\text { (anos) }\end{array}$ & $\begin{array}{c}\text { Modalida } \\
\text { de de } \\
\text { Ensino } \\
\text { adotada } \\
\text { após a }\end{array}$ & $\begin{array}{c}\text { Tipo de } \\
\text { Instituição } \\
\text { Superior }\end{array}$ & $\begin{array}{c}\text { Aquisição de } \\
\text { Ferramentas }\end{array}$ & $\begin{array}{c}\text { Houve } \\
\text { melhorias } \\
\text { Pandemia }\end{array}$ \\
\hline Docente 1 & $30-40$ & Até 4 & $\begin{array}{c}\text { Ensino } \\
\text { Remoto }\end{array}$ & $\begin{array}{c}\text { Pública e } \\
\text { Privada }\end{array}$ & Sim & Sim \\
discentes
\end{tabular}

Fonte: Dados da pesquisa, 2020.

Do quadro 1 acima, depreende-se que o perfil médio dos entrevistados com idade variando entre 30 e 40 anos, de 5 a 10 anos de atividade docente, utilizando o ensino remoto como mudança após a Pandemia, e que lecionam em instituições públicas e privadas.

Sobre a transição e principais dificuldades temos as seguintes declarações dos docentes:

Docente 1: "O ensino era semipresencial e passou a ser totalmente remoto." e que "O maior desafio foi o distanciamento presencial tornando mais difícil o acompanhamento dos acadêmicos."

Docente 2: "Na instituição pública a transição ocorreu de forma brusca e inesperada, sem recursos e formações no início do período pandêmico[...]" e "a falta de recursos tecnológicos disponibilizados [...], onde para conseguir realizar aulas de modo eficiente, tais recursos foram adquiridos com o meu próprio dinheiro, [...] criação de um ambiente especifico para desenvolver e gravar as aulas ou realiza-las em tempo real."

Docente 3: "No início foi muito confuso, não houve treinamento e não houve suspensão das aulas[...]" e ainda "manter a atenção dos alunos; a interação e espontaneidade. Substituição das avaliações presenciais/ trabalhos por avaliações remotas.".

Docente 4: "Através de resolução interna e comunicado aos alunos, feito diretamente pelos professores que optaram pelo ensino remoto" "Dificuldade de acesso à internet e 
equipamentos pelos alunos, falta de domínio das ferramentas de ensino remoto pelos professores"

Docente 5: "Reuniões com o corpo docente e coordenações de cursos. Logo após reuniões com alunos de cada curso. E finalmente tutoriais do funcionamento do ensino remoto na plataforma Google Sala de Aula." e "a falta de conhecimento deste tipo de ensino tanto docente como discente."

Docente 6: “Após 2 meses de paralisação [...], abertura de salas virtuais [...]” e encontrou dificuldades na "disponibilidade e entrosamento do profissional docente com as ferramentas necessárias ao ensino remoto"

Percebemos que como aspectos relevantes mencionados por todos os docentes temos as dificuldades técnicas com as ferramentas utilizadas e que sendo feitas de forma abrupta ou não, as mudanças não são acompanhadas de forma igual por todos.

Segundo Godoi et al. (2020), existem diversos desafios relacionados ao ensino remoto neste período de Pandemia, tais como: a adaptação e flexibilização em relação à uma nova forma de ensino e aprendizagem e utilização das ferramentas tecnológicas para o ensino, o que gera sentimento de insegurança, dúvidas e sobrecarga de trabalho, diz ainda que há dificuldades em motivar e engajar os discentes numa nova forma de relação de ensino.

Quanto as principais vantagens todos os participantes da pesquisa foram unânimes na indicação de que novos métodos nos possibilitam uma nova gama de possibilidades para ensino e avaliação, e maior interatividade, possibilitando maior assiduidade e visando reduzindo evasão escolar nesse período conturbado.

No que se refere as visões deste novo processo educacional, as respostas são variadas:

Docente 1: "Vejo como forma de consolidar o ensino remoto e mostrar sua eficácia naquilo que se propõe"

Docente 2: “Acredito que a Pandemia [...] irá revolucionar o meio educacional de uma maneira positiva" que "governos e instituições de iniciativas privadas invistam em recursos tecnológicos" ressaltando que "nem todos possuem acesso as plataformas digitais"

Docente 3: "Acho acessível, econômico e interessante, mas acho que exige um planejamento eficiente voltado para o ensino remoto e acho que alguns encontros presenciais e visitas técnicas são fundamentais"

Docente 4: "É um processo a ser aperfeiçoado, carece de maior capacitação e reestruturação dos estabelecimentos de ensino" 
Docente 5: "Muito ruim. Mostra que este tipo de educação é deficiente no processo de ensino-aprendizagem e que a sociedade como todo ainda não atingiu o século $21 \mathrm{em}$ ter acesso a tecnologias digitais com acesso para todos. Ter acesso a redes sociais via aparelhos telefônicos não implica avanço[...]"

Docente 6: "Percebo que é um processo válido, frente a realidade da Pandemia, porém percebo fragilidades no sistema como um todo[...]"

Neste contexto Arruda (2020), nos ensina que:

O Brasil não possui iniciativas no campo de tornar as tecnologias digitais como saberes necessários para uma formação transversal de alunos e alunas, como foi detectado na maioria dos países pertencentes a OCDE. Em um contexto no qual as tecnologias digitais tornam-se referências do setor produtivo, de serviços, de pesquisa e desenvolvimento, o momento considerado uma crise pode se configurar em possibilidade de fortalecer uma formação tecnológica que ultrapasse a dimensão do consumo e se torne crítica e produtiva de conhecimentos (escolares ou não) (ARRUDA, 2020, p 272-273).

Nos diz ainda Cavalcante et al. (2020) que esse processo de reflexão oportuniza muito mais do que resposta para as dúvidas. Ele aponta a descoberta de novas inquietações, capazes de gerar outras reflexões, explicitando o não esgotamento das possibilidades para responder uma demanda, sob a observação e atenção de múltiplas perspectivas.

Destaca-se ainda a dificuldade enfrentada na manutenção do interesse dos alunos e sua participação nas atividades em tempo real:

Docente 1: “[...] (alunos) desistiram por não dominarem as novas tecnologias"

Docente 4: "Os alunos têm baixa interação nas plataformas"

Docente 5: "na medida que os alunos não a acompanham em tempo real e nem aprendem com qualidade como nas aulas presenciais" que há "desânimo, descaso, angústia, etc." e ainda "os prazos a serem atingidos (pelos alunos) e a qualidade das respostas deixam a desejar"

Docente 6: "Os alunos têm diminuído a participação direta durante as aulas"

Cabe a discussão sobre as causas e consequências para a menor interatividade e participação, que podem advir desde a carências econômicas, dificuldades tecnológicas e até mesmo problemas psicológicos enfrentados pela comunidade discente.

Sobre a perspectiva de retorno as atividades nos modelos Pré-Pandemia os docentes relatam que:

Docente 1: "Não é possível prever com precisão os impactos a longo prazo, temos ainda estimativas[...]" e "para o conhecimento chegar a todas as classes sociais, será necessária a elaboração de políticas públicas mais eficazes que contemplem todas as camadas sociais" 
Docente 2: “[...]com novas possibilidades que irão diversificar a sala de aula e a maneira de ensinar, aprender e avaliar."

Docente 4: "[...] adoção de ensino híbrido"

Quanto ao tema, Valente et al. (2020), ensinam que nada substitui uma aula presencial e a convivência social que as instituições de ensino superior proporcionam, mas é preciso estar abertos ao aprender e experimentar.

\section{Considerações Finais}

Os dados obtidos nessa pesquisa revelam que os professores do ensino superior de instituições públicas e privadas tiveram que se reinventar durante o contexto da pandemia de COVID-19. Os encontros presenciais nas Instituições de Ensino Superior ficaram inviáveis e outras formas de ensino foram adotadas com o intuito de amenizar prejuízos durante o ano letivo de 2020.

As aulas deixaram de ser presenciais para ser virtuais, proporcionadas pelas Tecnologias Digitais de Informação e Comunicação (TDICs). O uso dessas ferramentas tecnológicas evidenciou dificuldades enfrentadas pelos professores que participaram dessa pesquisa, foram revelados problemas como: Distanciamento presencial tornando mais difícil o acompanhamento dos acadêmicos, falta de recursos tecnológicos, criação de um ambiente especifico para desenvolver e gravar as aulas ou realizá-las em tempo real, dificuldade de acesso à Internet e equipamentos pelos alunos e falta de conhecimento deste tipo de ensino tanto docente como discente. Como aspectos relevantes mencionados por todos os docentes as dificuldades técnicas não são assistidas de forma igual por todos.

Apesar de algumas instituições já utilizarem outras formas de ensino como aulas Remotas, EAD e semipresencial, as dificuldades de acesso para alunos e professores ficam evidentes quando esse modo de ensino passa a ser a única forma possível no momento, a pesquisa aponta através dos relatos dos professores que para um ensino que aborde instituições públicas e privadas em um momento pós Pandemia se faz necessário planos governamentais e privados que invistam em tecnologias e planejamentos eficientes voltados para o ensino remoto. Apesar dos esforços realizados pelos professores para ministrar aulas, o sistema ainda é falho, pois nem todos tem acesso a recursos tecnológicos e conseguem ter domínio das ferramentas das TDICs, mas que diante da realidade enfrentada atualmente esses foram os métodos encontrados para dar continuidade ao ensino. 
A pesquisa foi realizada com uma quantidade limitada de professores o que demanda um olhar mais cauteloso nos resultados encontrados, visto que o mesmo acontecimento pode ser avaliado de várias formas. O projeto aqui exposto teve como finalidade examinar os desafios que os professores universitários vêm enfrentando no ensino pós Pandemia, analisando as dificuldades encontradas atualmente nas plataformas de ensino.

Os resultados aqui encontrados revelam que a Pandemia da COVID-19 trouxe para o meio acadêmico descontentamento no modo de ensino devido à falta de infraestrutura das Instituições de Ensino Superior, dificuldades tecnológicas e até mesmo problemas psicológicos enfrentados pela comunidade discente, deixando claro que esse período é um dos mais incertos já enfrentados na esfera educacional, não só no Brasil, mas em todo o mundo.

\section{Referências:}

ALVES, J. R. MOREIRA. Universia Brasil. Educação superior a distância: uma análise de sua evolução no cenário brasileiro. Disponível em: http://www.universia.com.br/materia /materia.jsp?materia=9444. Acessado em: 02 de out. de 2020.

ARRUDA, E. P. Educação remota emergencial: elementos para políticas públicas na educação brasileira em tempos de Covid-19. EmRede-Revista de Educação a Distância, v. 7, n. 1, p. 257 $275,2020$.

BRASIL. Decreto $n^{\circ}$ 9057, de 25 de maio de 2017. Regulamenta o art. 80 da Lei $\mathbf{n}^{\circ}$ 9.394, de 20 de dezembro de 1996, que estabelece as diretrizes e bases da educação nacional. Disponível em: http://www.planalto.gov.br/ccivil_03/_Ato2015-2018/2017/Decreto/D9057.htm. Acesso em: 01 de out. de 2020.

BRASIL. Portaria $\mathbf{n}^{0}$ 343, de 17 de março de 2020. Dispõe sobre a substituição das aulas presenciais por aulas em meios digitais enquanto durar a situação de pandemia do Novo Coronavírus - COVID-19. Disponível em: http://www.in.gov.br/en/web/dou/-/portaria-n-343-de17-de-marco-de-2020-248564376. Acesso em: 02 out. 2020.

CAVALCANTE, A. S. P.; MACHADO, L. D. S.; FARIAS, Q. L. T.; PEREIRA, W. M. G.; SILVA, M. R. F. Educação superior em saúde: a educação a distância em meio à crise do novo coronavírus no Brasil. Avances en Enfermería, n. 1supl, 2020.

CERVO, A. L.; BERVIAN, P. A. Metodologia Científica. 5aed. São Paulo: Pearson Prentice Hall, 2002.

FREITAS, M. T. A. (2009) Cibercultura e formação de professores. Belo Horizonte: Autêntica. Editora. HODGES, Charles et al. The difference between emergency remote teaching and online learning. EDUCAUSE Review. 27 mar. 2020. Disponível em: https://er.educause.edu/ articles/2020/3/the-difference-between-emergency-remote-teaching-and-online-learning, 2020. Acesso em: 01 de outubro 2020. 
GIL, A. C. Como elaborar projetos de pesquisa. 6. ed. São Paulo: Atlas, 2017.

GODOI, M.; KAWASHIMA, L. B.; GOMES, L. A.; CANEVA, C. O ensino remoto durante a pandemia de covid-19: desafios, aprendizagens e expectativas dos professores universitários de Educação Física. Research, Society and Development, v. 9, n. 10, p. e4309108734-e4309108734, 2020.

GONÇALVES, H. de A. Manual de artigos científicos. São Paulo: Avercamp, 2004.

LAKATOS, E. M.; MARCONI, M. A. Metodologia Científica. 5aed. São Paulo: Atlas, 2010

LEITE, F. T. Metodologia Científica: métodos e técnicas de pesquisa - monografias, dissertações, teses e livros. Aparecida, São Paulo: Ideias e Letras, 2008.

LOPES, R. P.; FURKOTTER, M. Formação inicial de professores em tempos de TDIC: uma questão em aberto. Educ. rev., Belo Horizonte, v. 32, n. 4, p. 269-296, dez. 2016. Disponível em $<$ http://www.scielo.br/scielo.php?script=sci_arttext\&pid=S0102-46982016000400269\&lng=pt\& nrm=iso>. Acesso em 09 out. 2020. https://doi.org/10.1590/0102-4698150675.

MAIA, C.; MATTAR, J. ABC da EaD: a educação a distância hoje. Pearson Prentice Hall, 2008.

MALHOTRA, N. K. Pesquisa de marketing: uma orientação aplicada. $4^{\mathrm{a}}$ Ed. Porto Alegre: Bookman, 2004.

MARTINS, V.; ALMEIDA, J. Educação em tempos de pandemia no Brasil: saberes fazeres escolares em exposição nas redes e a educação on-line como perspectiva. Redoc, Rio de Janeiro, v. 4, n.2 p. 215-224, 2020. DOI: https://doi.org/10.12957/redoc.2020.51026.

OLIVEIRA, H. V; SOUZA, F. S. Do conteúdo programático ao sistema de avaliação: reflexões educacionais em tempos de pandemia (COVID-19). Boletim de Conjuntura (BOCA), v. 2, n. 5, 2020.

RODRIGUES, T. de A.; CÂNDIDO, E. L.; SOUZA, F. L. M. Education and sustainability in times of Covid-19 pandemic. International Journal for Innovation Education and Research, [S. 1.], v. 8, n. 9, p. 234-242, 2020. DOI: 10.31686/ijier.vol8.iss9.2623. Disponível em: https://ijier.net/ijier/article/view/2623. Acesso em: 10 out. 2020.

VALENTE, G. S. C.; MORAES, E. B.; SANCHEZ, M. C. O.; SOUZA, D. F.; PACHECO, M. C. M. D. O ensino remoto frente às exigências do contexto de pandemia: reflexões sobre a prática docente. Research, Society and Development, v. 9, n. 9, p. e843998153-e843998153, 2020.

\section{Como citar este artigo (Formato ABNT):}

CORDEIRO, Marcus Vinicius Cruz; COELHO, Nágila Batista; SARAIVA, Piedley Macedo; RODRIGUES, Tayronne de Almeida; PINHEIRO, Adriana de Alencar Gomes. Os Novos Desafios dos Professores de IES no Pós Pandemia: Um Estudo Realizado Com Docentes das Instituições de Ensino Superior de Juazeiro do Norte - Ceará. Id on Line Rev.Mult.Psic., Outubro/2020, vol.14, n.52, p. 703717. ISSN: 1981-1179.

Recebido: 20/10/2020; Aceito: 23/10/2020.

717 Id on Line Rev. Mult. Psic. V.14, N. 52, p. 703-717, Outubro/2020 - ISSN 1981-1179 Edição eletrônica em http://idonline.emnuvens.com.br/id 